\title{
A Study of the Application of Flipped Classroom Model in Translation Teaching to English Majors
}

\author{
Huan $\mathrm{Yu}$ \\ School of Foreign Languages of China West Normal University, \\ Nanchong, 637009, China
}

\begin{abstract}
With the development of the information technology and globalization, the flipped classroom model has aroused wide attention in China's education circle as an innovative teaching model. In the field of translation teaching for English majors, the traditional teaching model has been unable to adapt to the needs of the new era and a new teaching model is urgently needed. Therefore, the author tends to apply the flipped classroom teaching model in translation teaching to English majors so as to make the translation teaching out of predicaments. After analyzing the feasibility of the application of the flipped classroom model in translation teaching to English majors, the author constructed a new translation teaching model based on the notion of the flipped classroom model which could enhance English majors' translating abilities and improve the effectiveness of translation teaching.
\end{abstract}

Keywords-Translation Teaching; Flipped Classroom; Model; English Majors;

\section{INTRODUCTION}

Nowadays the translation industry is gradually upgrading to the translation industry. Large-scale international exchanges of cultural, economic and trade are arising from the demand for language services, which is the direct driving force to promote the rapid development of China's language service industry. Therefore, the demand for the amount of translation talents is increasing. At present, the situation of translation teaching especially in English majors is not optimistic. There are a series of problems in curriculum setting, teaching methods, assessment methods and students' knowledge structure, such as the unreasonable teaching content, too much translation practice of literary subjects, the limited knowledge of the students, the single model of teaching and assessment method, and the lack of translation technology module. What's more, the teacher, but not the students, is considered as the center in translation classroom, and the scope of translation knowledge, technical texts, the translation speed are not paid enough attention to. Finally, the disjunction between the information feedback and the teaching is serious. In a word, there is a large gap between the translation of professional graduates and career requirements. Therefore, we need to change the existing teaching model in the English translation teaching in order to get out the predicament.

\section{FEASIBILITy ANALYSIS OF THE APPLICATION OF FLIPPED Classroom Model in Translation TEACHING TO ENGLISH MAJORS}

\section{A. The Flipped Classroom Model and Its Characteristics}

Flipped classroom, a new teaching model which receives much concern, was first proposed by American chemistry teachers Jonathan Bergmann and Aaron Sams in 2007 and promoted in primary and secondary schools in the United States [1]. It subverts the traditional classroom teaching model, and has changed the roles of teachers and students. The Teaching process is very different. In the new model, the teaching is not carried out in the classroom, but in pre-class way by micro-class, and the students learns by themselves with the help of online Q \& A by teachers. The internalization and expansion of the knowledge is completed in the classroom time, which thus greatly improves students' self-learning ability [2]. The micro-class greatly enhances the interest of the student's learning because it is pithy and diverse in contents. In the traditional translation teaching model, the teaching content is generally single and boring, with many sentences lacking of contexts, which undermines students' interest in translation learning. However, in the flip classroom model, teachers can add a variety of elements in the micro-class, such as film video subtitles translation, popular song translation, celebrity speech translation, to make the translation teaching more interesting.

\section{B. An Analysis of Teaching Subjects in the Teaching Process}

Most teachers in English department have a higher degree of education, who have learnt a number of English courses in the undergraduate or graduate stage. They have a wide range of English-related knowledge and can carry out scientific researches in a professional aspect. Meanwhile, they have a unique perspective in the collection process of micro-class material and the ability for students to choose the excellent teaching resources, which is conducive to the implementation of the flip classroom model.

Compared with the non-English majors, English majors have better English foundation and more excellent basic skills in listening, speaking, reading, writing and translating. Because of their future employment needs, they need to have a broad English knowledge and the ability of using languages. In recent years, burnout in learning among English majors has attracted much attention in the educational circle. Due to the trivial knowledge in translation, a lot of repeated practices are necessary. However, many students are with learning-weariness mind. So how to make the boring 
English knowledge learning more lively and interesting is particularly important. In addition, English majors are deeply influenced by foreign teachers and western literary works, and with strong consciousness of democracy and freedom they accept new and advanced teaching forms more easily, which is conducive to the promotion of a new round teaching reform caused by the flipped classroom model.

\section{An Analysis of the Teaching Environment}

The small class teaching model along with language labs, computer lab, and multimedia classrooms in most universities meet the teaching requirements of the flipped classroom model. The class size of 20-30 students enables that every student is subject to the attention of teachers, namely teachers can answer each student's questions. In the limited class time, because the number of participants is relatively small, the exchange between teachers and students are more fully. Using the network and the language labs, students can explore the questions by themselves, and they can also study in a collaborative way.

\section{THE APPLICATION OF FLIPPED ClasSROOM MODEL IN TRANSLATION TEACHING TO ENGLISH MAJORS}

English translation teaching should pay appropriate attention to the basic theoretical translation knowledge and commonly used translation skills, which can guide students' translation practice. But the traditional translation teaching is often only focus on translation skills, and ignores the knowledge internalization and application abilities of students. The drawback of the translation teaching model in the classroom is that the students cannot get the teachers' timely guidance in the stage of absorbing and internalizing the knowledge, which leads to the obstruction of the knowledge internalization process. Under the guidance of constructivism theory, the flipped classroom model can solve this problem. It arranges the translation teaching including the basic theoretical translation knowledge, translation skills, etc. before the class in order to save the class time for students to internalize knowledge through independent inquiries and collaborative learning, and then review and consolidate knowledge they have learnt through the post-class summary exercises [3].

\section{A. The Important of Knowledge before the Class}

A relatively large amount of translation theory, translation methods, especially translation skills should be taught in the translation course. To save time in the classroom, teachers can teach students these contents by using the micro-class through the network platform before the class. As an important part in the class, the micro-class directly determines the effect of the pre-class knowledge transfer, which affects the design of the teaching activities in the class and the final learning effect [4]. The content of the micro-class is refined and its time is short. Each video should focus on one translation point, such as a translation technique, and the time should be controlled in about ten minutes. In addition to the micro-class, teachers should also provide the appropriate basic exercises before the class, so that students can test whether they can understand initially. If students have problems in watching videos or in pre-class exercises, they can talk to each other via the exchange platform, or they can also feedback to the teacher. For simple or individual issues, teachers can communicate with students via the platform; if there are difficulties or common problems, teachers can record them to give a unified answer in the classroom. The micro-class is applied to the flipped classroom model, in order to impart translation knowledge before the class, breaking the constraints of traditional translation teaching in time and space. At the same time it can reflect the personalized teaching (Fig. 1). Students can control the progress of teaching and suspend or play back the videos according to their own needs, which can solve the students' complaints about the teachers' teaching speed in the traditional classroom.

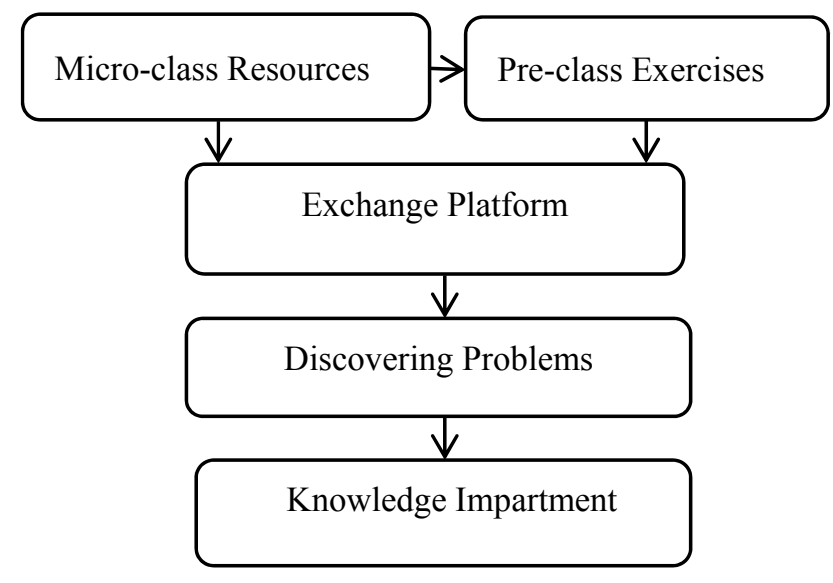

Fig. 1. The Pre-class Stage of the Flipped Classroom Teaching Model

\section{B. The Internalization of Knowledge in the Class}

In the traditional translation teaching model, most of the teachers' energy is used to realize the low-level cognitive goal of the teaching task, and only a small part of the energy is used to realize the high-level. While the flipped classroom model reverses the distribution of teachers' energy [5]. The flipped classroom model does not replace the teacher with videos. The basic skills of teachers are still an important guarantee for efficient teaching. Teachers should not only impart knowledge during the class, but also have the abilities, such as organization, supervision, guidance, as well as feedback and evaluation. In the classroom, teachers should first make a comment on the results of the pre-class exercises according to the feedback from the students, answering common or difficult questions. Secondly, teachers should design more intensive in-class exercises than pre-class exercises, as practice is a critical stage for students to achieve the internalization of translation knowledge. Under the guidance of the teacher, the students deal with the translation through independent inquiry and / or cooperative learning. Teachers should observe carefully in this process, and provide individual or collective counseling if necessary. After completing the exercises in the classroom, the teacher should encourage students to share the translation experience and make an objective and positive evaluation, so that students will once again strengthen their comprehension of the basic translation theory and translation skills in the translation achievements (Fig. 2). 


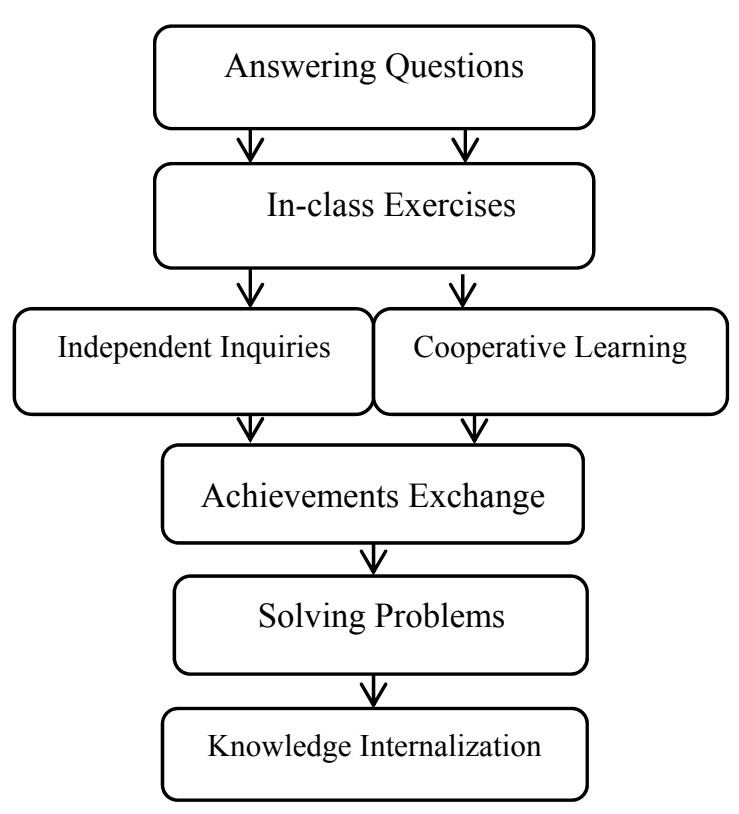

Fig. 2. The In-class Stage of the Flipped Classroom Teaching Model

\section{The Consolidation of Knowledge after Class}

The creative connotation of the flipped classroom model is embodied in the concept of "learning-first-and-teaching-next", which brings the most important learning process of internalization of knowledge from the post-class step in the traditional teaching to the class step in the new teaching model, so that teachers can provide timely and necessary help for students at this stage. Therefore, the flipped classroom teaching model is mainly composed of pre-class and in-class parts. However, students could gain new insights through restudying the old material. So it is also important to review lessons after class. Students will inevitably form a fragmented knowledge about translation through the pre-class and in-class learning. Students should comb these knowledge systems timely, and consolidate them with the post-class practice. If necessary, they can once again watch the micro-class to deepen the understanding of the contents they have learnt. After completing the knowledge impartment, internalization and consolidation, students can exchange ideas on the network platform to learn from each other. If there still exist some puzzled points, they can also discuss with students or teachers online or offline.

In the design process of the post-class teaching activities, there is an important aspect, which is learning evaluation (Fig. 3). Unlike the traditional achievements assessment, the flipped classroom model focuses more on the assessment of the process. Although the students' learning outcomes (translation quality) are still parts of the evaluation system, the proportion is relatively small. What's more, the evaluation system of the flipped classroom model should include self-assessment and mutual evaluation as well as the learning attitude and learning ability. Students evaluate themselves, classmates and teachers, and vice versa teachers evaluate themselves and their students. Students and teachers know their own evaluation results through the platform, which can supervise, urge and encourage each other [6]. In this way this new model forms a virtuous circle in the subsequent study and teaching process.

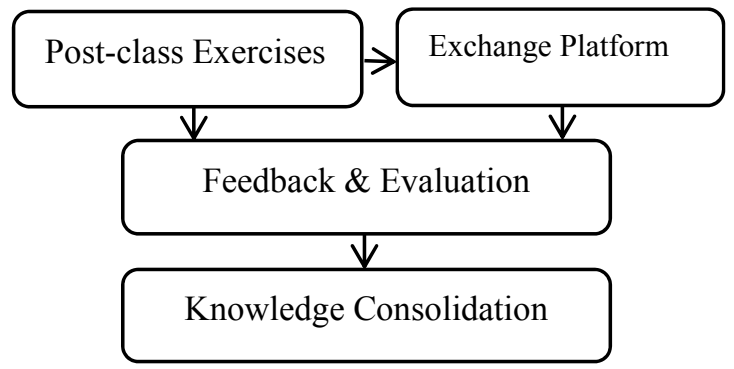

Fig. 3. The Post-class Stage of the Flipped Classroom Teaching Model

\section{CONCLUSION}

With the advancement of educational informatization, the flipped classroom model is increasingly being used in modern teaching. Based on the concept of learning-first-and-teaching-next, teachers complete the knowledge teaching before the class through the micro-class. And the class time is arranged to answer questions and solve problems for the students with teachers' guidance, as well as the knowledge internalization. This teaching model focuses on individual differences among students, who can arrange the learning time and the progress according to their own situation. At the same time, this teaching model provides students with active learning and cooperative discussion opportunities, imperceptibly cultivating students' comprehensive abilities, such as self-learning, speculation and innovation. The flipped classroom model subverts the traditional translation teaching model, which conforms to the current trend of informationization reform of education, and is beneficial for the translation teaching to get out of the predicament.

\section{ACKNOWLEDGEMENT}

This research was financially supported by Fundamental Scientific Research Funds for Young Teachers Projects of China West Normal University (Project No. 17D046)

\section{REFERENCES}

[1] Jonathan Bergmann, Aaron Sams, Flip Your Classroom: Reach Every Student in Every Class Every Day, USA: ISTE ASCD, 2012.

[2] Zhou Ping, "The Flipped Classroom Model and Its Theoretical Basis Based on Modern Educational Technology," J. Computer-assisted Foreign language Education, vol.3, pp. 72-76, 2015.

[3] Chen Yukun, Tian Aili, Introduction of the MOOC and Flipped Classroom, Shanghai: East China Normal University Press, 2014(In Chinese).

[4] Liu Rui, "The Design and Application of the 'Flipped Classroom' Teaching Model Based on Micro-class," J. Modern Educational Technology, vol. 5, pp.26-32, 2014.

[5] Zhu Zhiting, "Practice and Reflection on the Domestic Application of the Flipped Classroom Model," J. E-education Research, vol.6, pp. 66-72, 2015.

[6] Huang Yang, "A Brief Reflection of the Design of the Flipped Classroom Teaching Model," J. Modern Educational Technology, vol.12, pp. 100-106, 2014. 